\title{
Fault Distinguishability of Discrete Event Systems
}

\author{
Iwan Tabakow \\ Institute of Applied Informatics, Wroclaw University of Technology, Poland \\ iwan. tabakow@pwr.wroc.pl
}

\begin{abstract}
The subject of this paper is the theory of fault distinguishable discrete event systems. Any such system is modelled by a live, bounded, and reversible place-transition net. The notions of D-partition of the set of places $\mathrm{P}$ of a given place-transition net $\mathrm{N}$ and net k-distinguishability are first introduced. The system k-distinguishability measure is obtained in a unique way from the placeinvariant matrix. For a large value of $\mathrm{k}$, the system model is extended by using some set of additional places called test points. It is shown that the test point placement process will not change the above-assumed original net properties. Several examples are given.
\end{abstract}

\section{Introduction}

The use of Petri net models in diagnosis and reliable design of event-driven systems is a subject of interest to researchers since more than twenty years. In general, the most of the studies in this area focus attention on dynamical analysis concerning specification and implementation of some fault detection, fault diagnosis and/or fault recovery procedures, e.g. using partially stochastic Petri nets [1], or also using trace analysis [5], etc. The study of the system fault indistinguishability properties seems to be important because of the following two reasons. First, we have an additional possibility of describing the critical components of the considered system. Second, there exists a possibility of using some simple and at the same time exact tools for improving the system (self-) diagnosis capabilities in the early stages of its design $[2,8,9,10,11,12]$.

The subject of this paper is the theory of fault distinguishable discrete event systems. Any such system is modelled by a live, bounded, and reversible placetransition net. The notions of D-partition of the set of places $\mathrm{P}$ of a given placetransition net $\mathrm{N}$ and net k-distinguishability are first introduced. Next these two notions are extended to the set of all vertices, i.e. places and transitions of $\mathrm{N}$. So the problem of fault identification of the vertices of $\mathrm{N}$ is transformed as a problem of fault identification of the places of a new net $\mathrm{N}^{\prime}$ called a net simulator of $\mathrm{N}$. Any transition in $\mathrm{N}^{\prime}$ is assumed to be fault-free. Then the corresponding net place invariants are computed. The system k-distinguishability measure is obtained in a unique way from the place-invariant matrix. For a large value of $\mathrm{k}$, the system model is extended by using some set of additional places called test points. It is shown that the test point placement process will not change the above-assumed original net properties. Several examples are given. 


\section{Basic Notions}

In general any place-transition net $\mathrm{N}==_{\mathrm{df}}\left(\mathrm{T}, \mathrm{P}, \mathrm{A}, \mathrm{M}_{0}, \mathrm{~K}, \mathrm{~W}\right)$, where $(\mathrm{T}, \mathrm{P}, \mathrm{A})$ is a finite net containing sets of transitions, places, and arcs called also edges, $\mathrm{K}: \mathrm{P} \rightarrow$ $\left(I N_{\omega}-\{0\}\right)$ and $\mathrm{W}: \mathrm{A} \rightarrow \mathbb{N}$ are the corresponding place capacity and edge multiplicity (called also weight) functions, respectively. The initial marking vector $\mathrm{M}_{0}: \mathrm{P} \rightarrow I N_{\omega}$, where $\mathbb{N}$ denotes the set of all natural numbers, $I N==_{\mathrm{df}} \mathbb{N} \cup$ $\{0\}, I N_{\omega}==_{\mathrm{df}} I N \cup\{\omega\}$, and $\omega$ is an infinite number such that: $\omega+\mathrm{k}=$ $\omega$ and $\mathrm{k}<\omega$ (for any $\mathrm{k} \in I N$ ) [6,7]. The forward marking class of $\mathrm{N}$, i.e. [ $\mathrm{M}_{0}$ $>=_{\mathrm{df}}\left\{\mathrm{M} \in I N_{\omega}^{\mathrm{P}} / \exists \tau \in \mathrm{T}^{*}\left(\mathrm{M}_{0}[\tau>\mathrm{M})\right\}\right.$.

In the next considerations we shall assume $\mathrm{N}$ is a pure, live and bounded net. In the case of manufacturing systems the net reversibility property is also required. The net $P$ invariants are computed using $\underline{\mathrm{N}} \cdot \underline{\mathrm{i}}=\underline{0}$, where $\underline{\mathrm{N}}$ is the $P N$-connectivity matrix of $\mathrm{N}$. The support of any P-invariant $\mathrm{i}$ with respect to $\mathrm{N}$ (in short: wrt $\mathrm{N}$ ) is defined as follows: $\operatorname{supp}(\mathrm{i})==_{\mathrm{df}}\{\mathrm{p} \in \mathrm{P} / \underline{\mathrm{i}}(\mathrm{p}) \neq 0\} \subseteq \mathrm{P}$. Let $\ell$ be the set of all (positive) $\mathrm{P}$ invariants of $\mathrm{N}$ and $g \subseteq \ell$ is a subset. The P-invariant matrix of $\mathrm{N}$ wrt $g$ is introduced as follows: $g: g \times \mathrm{P} \rightarrow I N$, where $g(\mathrm{i}, \mathrm{p})={ }_{\mathrm{df}} \mathrm{i}(\mathrm{p}) \in I N$. For convenience only, we shall assume below that the P-cover $g$ of $\mathrm{N}$ is a set of all positive and minimal P-invariants. Also we shall use the notion of the revised P-invariant matrix of $\mathrm{N}$, defined as: $\varrho: \mathcal{g} \times \mathrm{P} \rightarrow\{0,1\}$, where $\varrho(\mathrm{i}, \mathrm{p})=_{\mathrm{df}} 1$ iff $\underline{\mathrm{i}}(\mathrm{p}) \neq 0$ [2]. For simplicity, it is assumed below $\mathrm{N}$ have a P-cover. Otherwise, this method is also applicable. In the last case some additional test points is necessary to be introduced.

\section{Net k-Distinguishability and Test Points}

Let $\left[\mathrm{M}_{0}>_{\alpha}=_{\mathrm{df}}\left[\mathrm{M}_{0}>\cup\left\{\mathrm{M}_{\alpha}\right\}\right.\right.$, where $\mathrm{M}_{0}$ is the initial marking and $\mathrm{M}_{\alpha}$ is a marking of $N$ such that $M_{\alpha} \notin\left[M_{0}>\right.$. We shall say $M_{\alpha}$ is a faulty marking. Since $M \underline{i}=M_{0} \underline{i}$ (for any $\mathrm{M} \in\left[\mathrm{M}_{0}>\right.$ and $\underline{\mathrm{i}} \in \mathrm{g}$ ) [6] then $\Delta \mathrm{M} \underline{\mathrm{i}}=0$, where $\Delta \mathrm{M}=\mathrm{d}_{\mathrm{df}} \mathrm{M}-\mathrm{M}_{0}$. The last property is satisfied for any P-invariant $\underline{i} \in \mathcal{g}$. Hence we can obtain $\underline{\mathcal{g}} \Delta \mathrm{M}^{\mathrm{T}}=\underline{0}$. Therefore for $\mathrm{M} \in\left[\mathrm{M}_{0}>_{\alpha}\right.$ the above equation may be violated. Thus we have: $2 \Delta \mathrm{M}^{\mathrm{T}}$ $=\underline{\mathrm{a}} \in\{0,1\}^{|\mathrm{g}|}$ (for any $\mathrm{M} \in\left[\mathrm{M}_{0}>_{\alpha}\right.$, obviously $\underline{\mathrm{a}}=\underline{0}$ iff $\mathrm{M} \in\left[\mathrm{M}_{0}>\right.$ ). Without losing any generality, below $(\underline{a})_{s} \neq 0$ are interpreted as $(\underline{a})_{s}=1(s \in\{1, \ldots,|g|\})$. Hence, in accordance with [4], any $(\underline{a})_{s}=1$ will correspond to some subset of places $\operatorname{supp}\left(\underline{i}_{s}\right) \subseteq P$ having a (potentially) faulty behaviour. Let $\mathrm{P} \supseteq \Omega(\underline{\mathrm{a}})=_{\mathrm{df}} \cap \operatorname{supp}\left(\underline{i}_{\mathrm{s}}\right) /(\underline{\mathrm{a}})_{\mathrm{s}}=1 \cap \cap$ $\operatorname{supp}\left(\underline{\mathbf{i}}_{\mathrm{s}}\right)^{\prime} /(\underline{\mathrm{a}})_{\mathrm{s}}=0$, where $\operatorname{supp}\left(\underline{\mathrm{i}}_{\mathrm{s}}\right)^{\prime}=_{\mathrm{df}} \mathrm{P}-\operatorname{supp}\left(\underline{\mathrm{i}}_{\mathrm{s}}\right)$ is the corresponding set complement operation. So, like [3] the notion of D-partition can be introduced. Below are used some basic notions given in [8].

\section{Definition 1}

By a D-partition of the set of places $\mathrm{P}$ of a given place-transition net $\mathrm{N}$ wrt the $\mathrm{P}$ cover $g$ of $\mathrm{N}$, denoted by $\Omega(\mathrm{N}, g)$, or $\Omega$ if $\mathrm{N}$ and $g$ are understood, we shall mean the (multi) family $\Omega==_{\mathrm{df}}\left\{\Omega(\underline{a}) / \underline{a} \in\{0,1\}^{|/|}\right\}$. 
Proposition 1 [8]

(a) $\Omega(\underline{0})=\varnothing$,

(b) $\forall \underline{a}, \underline{b} \neq \underline{0}(\underline{a} \neq \underline{b} \Rightarrow \Omega(\underline{a}) \cap \Omega(\underline{b})=\varnothing)$, and

(c) $\cup \Omega(\underline{a}) / \underline{a} \in\{0,1\}^{|g|}=P$.

The notion of a k-distinguishable place-transition net under a D-partition of the set of places $\mathrm{P}$ of $\mathrm{N}$ is given in the next definition.

Definition 2

The Petri net $\mathrm{N}$ is a $k$-distinguishable net under $\Omega$ iff

(i) $\exists \Omega(\underline{a}) \in \Omega(|\Omega(\underline{a})|=k)$ and

(ii) $\forall \Omega(\underline{a}) \in \Omega(|\Omega(\underline{a})| \leq \mathrm{k})$.

The support of any D-partition is defined as follows: $\operatorname{supp}(\Omega)=_{\mathrm{df}}\{\Omega(\underline{\mathrm{a}}) \in \Omega /$ $\Omega(\underline{a}) \neq \varnothing\}$. Let $\pi(\mathrm{P})$ be the partition generated by the set of subsets of places (i.e. classes), such that each class consists of places having identical columns in the revised P-invariant matrix $\varrho$ of $\mathrm{N}$. The following proposition is satisfied (a more formal proof is given in [11]).

Proposition 2 [2]

$\operatorname{supp}(\Omega)=\pi(\mathrm{P})$.

Definition 3

Let $\mathrm{N}$ be a place-transition net. Then $\mathrm{N}$ is a $k$-distinguishable net iff $\exists \mathrm{N}^{\prime}\left(\mathrm{N}^{\prime}\right.$ is a net simulator of $\mathrm{N}$ and $\mathrm{N}^{\prime}$ is a k-distinguishable net under $\Omega^{\prime}$ ).

\section{Definition 4}

Let $\mathrm{p}_{\mathrm{k}_{0}} \in \mathrm{P}$ be a given place of $\mathrm{N}$ such that the pre-set $\bullet \mathrm{p}_{\mathrm{k}_{0}}==_{\mathrm{df}}\left\{\mathrm{t}_{1}\right\}$ and the post-set $\mathrm{p}_{\mathrm{k}_{0}} \bullet=_{\mathrm{df}}\left\{\mathrm{t}_{2}\right\}$, where $\mathrm{t}_{1}$ and $\mathrm{t}_{2}$ are two different transitions of $\mathrm{N}$. The additional place $\mathrm{p}_{\mathrm{k}_{0}}{ }^{\prime} \in \boldsymbol{\bullet}^{\cdot} \mathrm{t}_{1} \cap \mathrm{t}_{2} \bullet$ is said to be a test point associated with $\mathrm{p}_{\mathrm{k}_{0}}$ iff the initial marking $\hat{\mathrm{M}}_{0}$ of the obtained net $\hat{\mathrm{N}}$ is specified as follows: $\hat{\mathrm{M}}_{0}(\mathrm{p})=_{\mathrm{df}}$ if $\mathrm{p}=\mathrm{p}_{\mathrm{k}_{0}}$ ' then $\max \left\{\mathrm{M}\left(\mathrm{p}_{\mathrm{k}_{0}}\right) / \mathrm{M} \in\left[\mathrm{M}_{0}>\right\}-\mathrm{M}_{0}\left(\mathrm{p}_{\mathrm{k}_{0}}\right)\right.$ else $\mathrm{M}_{0}(\mathrm{p})$ fi (for any $\left.\mathrm{p} \in \hat{\mathrm{P}}={ }_{\mathrm{df}} \mathrm{P} \cup\left\{\mathrm{p}_{\mathrm{k}_{0}}{ }^{\prime}\right\}\right)$.

It can be observed that in some cases the considered Petri net may be maximally indistinguishable, e.g. a net which is a state-machine net and a marked graph at the same time. Then the corresponding P-cover will contain only one P-invariant having all components equal to one.

\section{Proposition 3}

Let $\mathrm{N}$ be a directed elementary cycle having $\mathrm{m}$ places $(\mathrm{m}>1)$. Then $\mathrm{N}$ becomes $(2 \mathrm{~m}-\mathrm{r})$-distinguishable if $\mathrm{r}$ additional test points are placed $(1 \leq \mathrm{r} \leq 2 \mathrm{~m}-1)$. 
A generalisation of Definition 3 for non-ordinary place-transition nets (i.e. nets having some edges a $\in A$ with weights $w(a) \neq 1)$ is omitted here. Any such generalisation of the last definition for place-transition nets, which are not ordinary, would require an isomorphism between the corresponding reachability graphs $R G(N)$ and $\operatorname{RG}(\hat{\mathrm{N}})$ (see Example 1 and Theorem 2 given below). Let $\mathrm{P}_{\underline{a}}={ }_{\mathrm{df}} \Omega(\underline{a}$ ) (for any $\left.\underline{\mathrm{a}} \in\{0,1\}^{|g|}\right)$. Obviously $\mathrm{P}_{\underline{a}} \in \operatorname{supp}(\Omega)$ if $\mathrm{P}_{\underline{a}} \neq \varnothing$.

\section{Definition 5}

Let $\mathrm{P}_{\underline{a}} \neq \varnothing, \mathrm{T}_{\underline{a}}={ }_{\mathrm{df}} \bullet \mathrm{P}_{\underline{a}} \cup \mathrm{P}_{\underline{a}} \bullet$ and $\mathrm{A}_{\underline{a}}={ }_{\mathrm{df}} \mathrm{A} \cap\left(\left(\mathrm{T}_{\underline{a}} \times \mathrm{P}_{\underline{a}}\right) \cup\left(\mathrm{P}_{\underline{a}} \times \mathrm{T}_{\underline{a}}\right)\right)$. The corresponding subnet $\mathrm{N}_{\underline{a}}={ }_{d f}\left(\mathrm{~T}_{\underline{a}}, \mathrm{P}_{\underline{a}}, \mathrm{~A}_{\underline{a}}\right)$ of $\mathrm{N}$ is called a graphical representation of $\mathrm{P}_{\underline{a}}$. We shall say $\mathrm{N}_{\underline{a}}$ is a marked graph component (or $M G$ component) iff $\forall \underline{p} \in \mathrm{P}_{\underline{\mathrm{a}}}(|\bullet \mathrm{p}|=|\mathrm{p} \bullet|=1)$. The subset of places $\mathrm{P}_{\underline{\mathrm{a}}}$ is said to be a $M G$-component generator.

Theorem 1[10]

Assume that $\mathrm{N}$ a live and bounded place-transition net having $|\mathrm{P}| \geq 2$ and $\operatorname{supp}(\Omega)==_{\mathrm{df}}\left\{\mathrm{P}_{\underline{\mathrm{a}}_{1}}, \mathrm{P}_{\underline{\mathrm{a}}_{2}}, \ldots, \mathrm{P}_{\underline{\mathrm{a}}_{n}}\right\}$, where $1 \leq \mathrm{n}<|\mathrm{P}|$. If any $\mathrm{P}_{\underline{\mathrm{a}}} \in \operatorname{supp}(\Omega)$ is a MG-component generator then $\mathrm{N}$ can be transformed into a 1-distinguishable net by using $(|\mathrm{P}|-\mathrm{n})$ test points.

It is obvious that any P-invariant in $\mathrm{N}$ can be extended as a P-invariant in $\hat{\mathrm{N}}$ by assuming 0 's relating to the corresponding test point components, i.e. the following proposition is satisfied.

\section{Proposition 4}

If $\underline{i}$ is a $\mathrm{P}$-invariant in $\mathrm{N}$ then $\hat{\mathrm{i}}=_{\mathrm{df}}(\underline{\mathrm{i}}, \underline{\underline{0}})$ is a $\mathrm{P}$-invariant in $\hat{\mathrm{N}}$, where the vector size of $\underline{0}$ is related to the number of used test points.

\section{Proposition 5}

If $\mathrm{p}_{\mathrm{k}_{0}}$ ' is a test point associated with $\mathrm{p}_{\mathrm{k}_{0}} \in \mathrm{P}$ in $\mathrm{N}$ then $\hat{\mathrm{i}}_{\mathrm{k}_{0}}$ is a $\mathrm{P}$-invariant in $\hat{\mathrm{N}}$, where $\operatorname{supp}\left(\hat{\mathrm{i}}_{\mathrm{k}_{0}}\right)=\left\{\mathrm{p}_{\mathrm{k}_{0}}, \mathrm{p}_{\mathrm{k}_{0}}{ }^{\prime}\right\}$.

\section{Proof}

Assume that $\mathrm{p}_{\mathrm{k}_{0}}$ is a test point associated with $\mathrm{p}_{\mathrm{k}_{0}} \in \mathrm{P}$ in N. According to Definition 4 $\mathrm{p}_{\mathrm{k}_{0}}{ }^{\prime}\left(\mathrm{p}_{\mathrm{k}_{0}}\right)$ is at the same time an input (output) place to $\mathrm{t}_{1}$ and an output (input) place to $t_{2}$. By definition, a vector $\underline{x}$ is a P-invariant iff $\underline{\hat{N}} \cdot \underline{x}=\underline{0}$. Hence iff $\underline{\hat{t}} \cdot \underline{x}=\underline{0}$ (for any row-vector $\underline{\hat{t}}$ of $\underline{\hat{N}})$. And so, there exist exactly two equations related to $t_{1}\left(t_{2}\right)$ of the following form: $\ldots-\mathrm{x}_{\mathrm{p}_{\mathrm{k} 0}}{ }^{\prime}\left(+\mathrm{x}_{\mathrm{p}_{\mathrm{k} 0}}{ }^{\prime}\right) \ldots+\mathrm{x}_{\mathrm{p}_{\mathrm{k} 0}}\left(-\mathrm{x}_{\mathrm{p}_{\mathrm{k} 0}}\right) \ldots=0$. The P-invariant

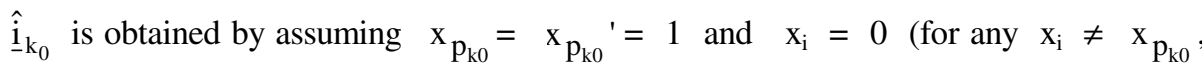

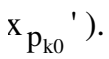




\section{Proposition 6}

If $g$ is a P-cover of $\mathrm{N}$ then $\hat{g}=\mathrm{df}_{\mathrm{df}} \mathrm{g} \cup\left\{\hat{\mathrm{i}}_{\mathrm{k}_{0}}\right\}$ is a P-cover of $\hat{\mathrm{N}} . \quad\{$ Prop.5 $\}$

In a natural manner, the last two propositions can be extended for non-ordinary placetransition nets. This is illustrated in the next example.

\section{Example 1}

Consider the hypothetical fragment shown in Figure 1(a) below. Let $\mathrm{p}^{\prime}$ be a test point associated with $p \in P$ in $N$ and $\hat{i}$ be a P-invariant in $\hat{N} \operatorname{such}$ that $\operatorname{supp}(\hat{\mathrm{i}})==_{\mathrm{df}}$ $\left\{p, p^{\prime}\right\}$. Using $\underline{\hat{N}} \cdot \underline{\hat{i}}=\underline{0}$ (assuming $\underline{\hat{i}}(q)=_{d f} 0$, for $q \in P-\operatorname{supp}(\hat{i})$ ) the following two equations can be obtained:

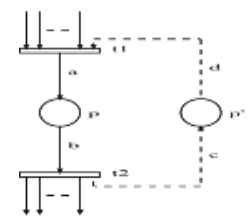

(a)

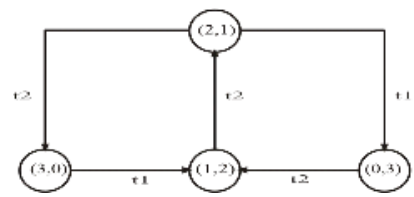

(c) $\mathrm{RG}(\mathrm{N})$

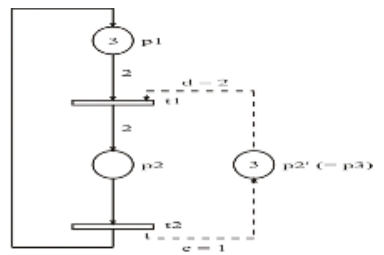

(b)

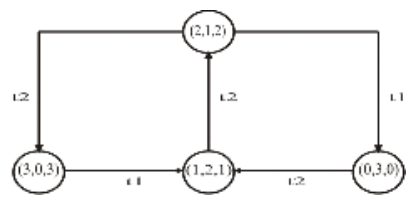

(d) $\operatorname{RG}(\hat{\mathrm{N}})$

Fig. 1. A hypothetical fragment of non-ordinary place-transition net (a), an example test point placement (b), and the corresponding reachability graphs $\operatorname{RG}(\mathrm{N})$ and $\operatorname{RG}(\hat{\mathrm{N}})$ (c and d, respectively)

$$
\begin{aligned}
& \mathrm{a} \cdot \underline{\hat{i}}(\mathrm{p})-\mathrm{d} \cdot \underline{\hat{i}}\left(\mathrm{p}^{\prime}\right)=0 \\
& -\mathrm{b} \cdot \underline{\hat{\mathrm{i}}}(\mathrm{p})+\mathrm{c} \cdot \underline{\hat{\mathrm{i}}}\left(\mathrm{p}^{\prime}\right)=0
\end{aligned}
$$

Since the edge multiplicities $\mathrm{a}$ and $\mathrm{b}$ of $\mathrm{N}$ are a priori given then $\mathrm{d}$ and $\mathrm{c}$ can be defined in a unique way by assuming $\hat{\mathrm{i}}(\mathrm{p})=\underline{\hat{\mathrm{i}}}\left(\mathrm{p}^{\prime}\right)=1$. Hence: $\mathrm{d}==_{\mathrm{df}} \mathrm{a}$ and $\mathrm{c}$ $=_{\mathrm{df}} \mathrm{b}$. The obtained P-invariant $\hat{\mathrm{i}}$ is minimal and positive.

An example test point placement is shown in Figure 1(b) where an example live, bounded, and reversible place-transition net is presented. Assume that $T=\left\{\mathrm{t}_{1}, \mathrm{t}_{2}\right\}$ is a fault-free. According to Proposition 2 the considered net $\mathrm{N}$ is 2-distinguishable wrt the P-invariant $\underline{\mathrm{i}}=(1,1)$ having two identical columns. Let $\mathrm{p}_{3}=_{\mathrm{df}} \mathrm{p}_{2}^{\prime}$ be a test point such that $\hat{M}_{0}\left(\mathrm{p}_{3}\right)={ }_{\mathrm{df}} \max \left\{\mathrm{M}\left(\mathrm{p}_{2}\right) / \mathrm{M} \in\left[\mathrm{M}_{0}>\right\}-\mathrm{M}_{0}\left(\mathrm{p}_{2}\right)=3-0=3\right.$. 
According to Proposition $4 \hat{\mathrm{i}}=_{\mathrm{df}}(1,1,0)$ is a P-invariant in $\hat{\mathrm{N}}$. Using $\underline{\hat{\mathrm{N}}} \cdot \underline{\mathrm{x}}=\underline{0}$ the following two equations can be obtained:

$$
\begin{gathered}
-2 \cdot \mathrm{x}_{1}+2 \cdot \mathrm{x}_{2}-\mathrm{d} \cdot \mathrm{x}_{3}=0 \\
\mathrm{x}_{1}-\mathrm{x}_{2}+\mathrm{c} \cdot \mathrm{x}_{3}=0
\end{gathered}
$$

Let $\mathrm{x}_{1}=0, \mathrm{x}_{2}=\mathrm{x}_{3}=1$. Then $\mathrm{d}=2$ and $\mathrm{c}=1$. In accordance with Proposition $6 \underline{\hat{i}}_{2}={ }_{\mathrm{df}}(0,1,1)$ is another P-invariant where $\operatorname{supp}\left(\underline{\hat{\mathrm{i}}}_{2}\right)=\left\{\mathrm{p}_{2}, \mathrm{p}_{3}\right\}$. In fact, we have $\hat{\mathrm{M}}\left(\mathrm{p}_{2}\right)+\hat{\mathrm{M}}\left(\mathrm{p}_{3}\right)=3$ (for any $\hat{\mathrm{M}} \in\left[\hat{\mathrm{M}}_{0}>\right.$ in $\left.\hat{\mathrm{N}}\right)$. The obtained P-invariant matrix $\hat{y}=\left[\begin{array}{lll}1 & 1 & 0 \\ 0 & 1 & 1\end{array}\right]$ has all columns different and $\hat{\mathrm{N}}$ is 1-distinguishable. The corresponding reachability graphs $\mathrm{RG}(\mathrm{N})$ and $\mathrm{RG}(\hat{\mathrm{N}})$ are shown in the above Figure 1(c) and (d), respectively. It can be observed that any $\mathrm{M}$ of $\mathrm{N}$ is a prefix of the corresponding $\hat{\mathrm{M}}$ of $\hat{\mathrm{N}}$ and the last two reachability graphs are isomorphic. Hence, the original boundedness, liveness, and reversibility properties of $\mathrm{N}$ are preserved in $\hat{\mathrm{N}}$.

\section{Example 2}

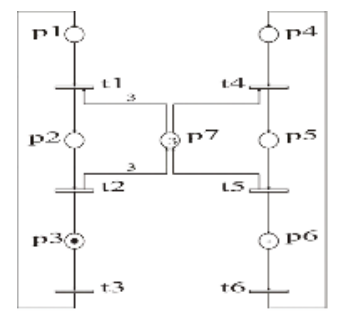

(a) $\mathrm{N}$

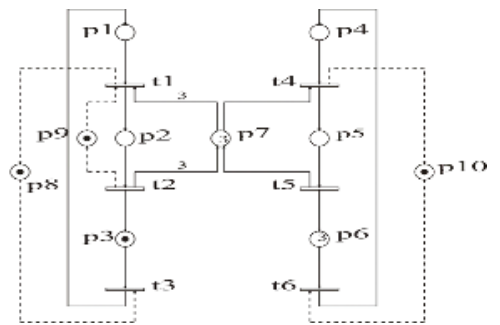

(b) $\hat{\mathrm{N}}$

Fig. 2. A system consisting of one write- and three read-authorised processes (a) and a net distinguishability improving using test points $\mathrm{p}_{8}, \mathrm{p}_{9}$ and $\mathrm{p}_{10}(\mathrm{~b})$

Consider $\mathrm{N}$ of Figure 2(a) describing the behaviour of a system consisting of one write- and three read-authorised processes [4,6,7]. The following P-cover can be obtained: $g=\left\{\underline{i}_{1}, \underline{i}_{2}, \underline{i}_{3}\right\}$, where: $\underline{\underline{i}}_{1}=(1,1,1,0,0,0,0), \underline{\underline{i}}_{2}=(0,0,0,1,1,1,0)$ and $\underline{\dot{i}}_{3}$ $=(1,4,1,0,1,0,1) .$. According to Proposition $2, \mathrm{~N}$ is 3-distinguishable. The obtained test point improving is shown in Figure 2(b). The net $\mathrm{N}$ becomes 2-distinguishable for $\mathcal{g}=\left\{\underline{\mathrm{i}}_{2}, \underline{\mathrm{i}}_{3}, \underline{\mathrm{i}}_{4}\right\}$ or also $\mathrm{g}=\left\{\underline{\mathrm{i}}_{1}, \underline{\underline{i}}_{2}, \underline{\mathrm{i}}_{4}\right\}$, where $\underline{\mathrm{i}}_{4}=(0,3,0,0,1,0,1)$. In the last case the number of test points can be reduced to 2 (e.g. by removing $\mathrm{p}_{9}$ ). \{Df.2, Prop.2, T1 $\}$

\section{Theorem 2}

Let $\mathrm{N}$ be live, bounded, and reversible place-transition net and $\mathrm{p}_{\mathrm{k}_{0}}$ ' be a test point associated with $\mathrm{p}_{\mathrm{k}_{0}}$. Then $\hat{\mathrm{N}}$ is also live, bounded, and reversible. 
Proof

Without losing any generality, assume that $g$ is a P-cover of $\mathrm{N}$. Then $\hat{y}={ }_{\mathrm{df}} g \cup$ $\left\{\hat{\mathrm{i}}_{\mathrm{k}_{0}}\right\}$ is a P-cover of $\hat{\mathrm{N}}$.Otherwise, a P-cover of $\mathrm{N}$ can be obtained by assuming additional test points. According to Definition $4 \hat{\mathrm{M}}_{0}$ is bounded. Hence $\hat{\mathrm{N}}$ is bounded.

Let $\bar{M}==_{\mathrm{df}} \max \left\{\mathrm{M}\left(\mathrm{p}_{\mathrm{k}_{0}}\right) / \mathrm{M} \in\left[\mathrm{M}_{0}>\right\}\right.$ and $\mathrm{T}(\mathrm{M})=_{\mathrm{df}}\{\mathrm{t} \in \mathrm{T} / \mathrm{t}$ is $\mathrm{M}-$ enabled in $N$ \}. Assume that $t_{1} \in T(M)$. Hence $t_{1} \in T(\hat{M})$ iff $\hat{M}\left(p_{k_{0}}\right)+a \leq$ $\bar{M}$ and $\hat{\mathrm{M}}\left(\mathrm{p}_{\mathrm{k}_{0}}{ }^{\prime}\right) \geq \mathrm{a}$ (see the above Figure 1(a) assuming $\mathrm{p}=\mathrm{df}_{\mathrm{k}_{0}}$ and $\mathrm{p}^{\prime}={ }_{\mathrm{df}}$ $\mathrm{p}_{\mathrm{k}_{0}}{ }^{\prime}$ ). However, in accordance with Definition $4 \hat{\mathbf{M}}\left(\mathrm{p}_{\mathrm{k}_{0}}\right)=\mathbf{M}\left(\mathrm{p}_{\mathrm{k}_{0}}\right)$ (for any $\mathrm{M} \in\left[\mathrm{M}_{0}>\right)$. Hence $\hat{\mathrm{M}}\left(\mathrm{p}_{\mathrm{k}_{0}}\right)+\mathrm{a}=\mathrm{M}\left(\mathrm{p}_{\mathrm{k}_{0}}\right)+\mathrm{a} \leq \bar{M}$. Moreover, $\hat{\mathrm{i}}_{\mathrm{k}_{0}}$ is a Boolean vector. Then $\hat{\mathrm{M}}\left(\mathrm{p}_{\mathrm{k}_{0}}\right)+\hat{\mathrm{M}}\left(\mathrm{p}_{\mathrm{k}_{0}}{ }^{\prime}\right)=\bar{M}$ (for any $\hat{\mathrm{M}} \in\left[\hat{\mathrm{M}}_{0}>\right.$ in $\hat{\mathrm{N}}$ ). Hence: $\mathrm{a}+\hat{\mathbf{M}}\left(\mathrm{p}_{\mathrm{k}_{0}}\right)+\hat{\mathrm{M}}\left(\mathrm{p}_{\mathrm{k}_{0}}\right)=\bar{M}+\mathrm{a}$. Since $\mathrm{a}+\hat{\mathrm{M}}\left(\mathrm{p}_{\mathrm{k}_{0}}\right) \leq \bar{M}$ then $\bar{M}+\hat{\mathrm{M}}\left(\mathrm{p}_{\mathrm{k}_{0}}\right) \geq \bar{M}+$ a. Hence $\hat{\mathrm{M}}\left(\mathrm{p}_{\mathrm{k}_{0}}{ }^{\prime}\right) \geq \mathrm{a}$ and $\mathrm{t}_{1} \in \mathrm{T}(\hat{\mathrm{M}})$.

Assume now that $t_{2} \in T(M)$. Hence $t_{2} \in T(\hat{M})$ iff $\hat{M}\left(p_{k_{0}}\right) \geq b$ and $\hat{\mathrm{M}}\left(\mathrm{p}_{\mathrm{k}_{0}}\right)+\mathrm{b} \leq \bar{M}$. Since $\hat{\mathrm{M}}\left(\mathrm{p}_{\mathrm{k}_{0}}\right)=\mathrm{M}\left(\mathrm{p}_{\mathrm{k}_{0}}\right)$ the first condition $\hat{\mathrm{M}}\left(\mathrm{p}_{\mathrm{k}_{0}}\right) \geq \mathrm{b}$ is satisfied. Hence, using $\hat{\mathrm{M}}\left(\mathrm{p}_{\mathrm{k}_{0}}\right)+\hat{\mathrm{M}}\left(\mathrm{p}_{\mathrm{k}_{0}}\right)=\bar{M}$ we can obtain: $\mathrm{b}+$ $\hat{\mathrm{M}}\left(\mathrm{p}_{\mathrm{k}_{0}}\right) \leq \bar{M}$.

Hence: $\mathrm{t} \in \mathrm{T}(\mathrm{M})$ iff $\mathrm{t} \in \mathrm{T}(\hat{\mathrm{M}})$ (for $\mathrm{t} \in\left\{\mathrm{t}_{1}, \mathrm{t}_{2}\right\}$ ). And so, the liveness and reversibility properties of $\mathrm{N}$ are preserved in $\hat{\mathrm{N}}$.

$\{$ Df.4, Prop.5, Prop.6\} $\square$

Test points can be placed independently each other. Hence Theorem 2 can be generalised for any finite subset of such points.

\section{Conclusions}

The above-considered approach gives a possibility of fault isolation in concurrent systems. This process is realised by using the Petri net model of the considered system. The degree of accuracy to which faults can be located, i.e. the diagnostic resolution is given in unique way by the obtained k-distinguishability measure. The complexity of the proposed method depends on the efficiency of the existing algorithms for computation of the P-cover, i.e. the set of P-invariants covering $\mathrm{N}$. The choice of diagnosis strategies, i.e. combinational or also sequential is depending on the used time requirements for testing. Moreover, an additional cost-minimisation can be obtained by assuming the considered test point set as a "hardcore". This approach 
can be extended for higher level Petri nets, e.g. such as coloured nets or also to design self-diagnosable circuit realisations of Boolean interpreted Petri nets.

\section{References}

1. Aghasaryan A., Fabre E., Benveniste A., Boubour R. and Jard C., Fault detection and diagnosis in distributed systems : an approach by partially stochastic Petri nets. Discrete Event Dynamic Systems 8, 2 (Special issue on Hybrid Systems), June 1998, pages 203-231.

2. Immanuel B. and Rangarajan K., System diagnosis and k-distinguishability in Petri nets. Private communication, India (2001),14pp.

3. Mayeda W., Graph Theory. John Wiley \& Sons,Inc.,New York (1972)523 - 557.

4. Murata T., Petri nets and their applications. Journal Soc. Instrum. Control Eng. 22,Japan (1983)6572.

5. Pietschker A. and Ulrich A., A light-weight method for trace analysis to support fault diagnosis in concurrent systems. Journal of Systemics, Cybernetics and Informatics,vol.1 no.6 (2003) 6pp.

6. Reisig W., Petri Nets.An Introduction. Springer-Verlag (1985)15,62 - 66.

7. Reisig W., A Primer in Petri Net Design. Springer-Verlag (1992)25 - 33.

8. Tabakow I.G., Using Petri net invariants in system diagnosis. Petri Net Newsletter 58,Germany (2000)21 - 31 .

9. Tabakow I.G., An introduction to the place-transition nets $k$-distinguishability. Concurrency, Specification and Programming. Workshop.vol.2,Humboldt-Universität zu Berlin, Germany (2002),355 - 369.

10. Tabakow I.G., Using Test Points to Improve the Place -Transition Net $k$ Distinguishability. Proc. of the $7^{\text {th }}$ World Multiconference on Systemics, Cybernetics and Informatics SCI 2003, Orlando, Florida USA, July 27-30, vol. IX: Computer Science and Engineering II (2003), 173 - 178.

11. Tabakow I.G., Using place invariants to isolate faults in concurrent systems. Petri Net Newsletter 68, Germany (2005)10 - 20.

12. Tabakow I.G., Fault Diagnosis of Discrete Event Systems Using Place Invariants. Ninth International Conference on Knowledge-Based \& Intelligent Information \& Engineering Systems KES'2005, Invited Session on Communicative Intelligence, Melbourne, Australia, September 14 - 16 (2005) in: LNCS, Springer-Verlag vol. 3682 (2005) 541 - 547.

13. Zhou M.C. and DiCesare F., Petri net synthesis for discrete event control of manufacturing systems. Kliwer Academic, Boston (1993)233pp. 